\title{
La nueva regulación aduanera: ¿solución a los problemas del comercio exterior colombiano?
}

\section{The new Customs Regulation: ¿Solution to the problems of Foreing Trade?}

\author{
JuAn Diego CANo GARCíA ${ }^{1}$
}

\section{Resumen}

El presente artículo aborda los principales cambios incorporados en la legislación aduanera y de comercio exterior a través de la reciente normativa expedida, resaltando los conceptos y operaciones que, el autor considera, impactarán de forma positiva en la facilitación y simplificación del comercio. Por otra parte, señala los obstáculos que ha presentado la adopción de la nueva regulación con el fin de presentar un panorama sobre lo cerca o lejos que está Colombia de la implementación y cuándo serán perceptibles sus efectos. Además, realiza una breve reseña, desde el punto de vista del sector privado, de las mesas de trabajo desarrolladas durante la construcción del decreto.

Palabras clave: Aduanas; Decreto 390 de 2016; Comercio exterior; Impacto comercial.

\section{Abstract}

This article aims to approach the main changes incorporated in customs legislation and foreign trade through the recently issued regulations, highlighting the concepts and operations, which the author believes, will impact positively on facilitation and trade simplification. On the other hand, it will point to the present obstacles for the adoption of the new regulation in order to provide an overview on how close or far, that we are of achieve it and when its effects will be perceptible. In addition, it performs a brief overview, from the point of view of the private sector, on the work tables developed during the construction of decree.

Keywords: Customs regulation; Foreing Trade; Comercial Impact.

\footnotetext{
${ }^{1}$ Juan Diego Cano García. Abogado de la Universidad Libre de Pereira, especialista en Derecho Aduanero de la Universidad Externado de Colombia. Actualmente se desempeña como Director de Asuntos Legales de Analdex. Correo-e: jcano@analdex.org. Artículo recibido el 2 de agosto de 2016. Aprobado el 20 de septiembre de 2016. Para citar el artículo: Cano, J. (2016) "La nueva regulación aduanera ¿solución a los problemas de comercio exterior colombiano?”, en Revista de Derecho Fiscal n. ${ }^{\circ}$ 9, Bogotá: Universidad Externado de Colombia. pp. 29-42. DOI: http://dx.doi.org/10.18601/16926722.n9.03
} 
Sumario. I. Introducción. II. Estado actual y problemática. 1. Colombia: Perspectivas empresariales. Serie del ITC sobre las medidas no arancelarias. 2. Doing business. 3. Índice de Desempeño Logístico. III. Principales cambios de la nueva regulación aduanera. 1. Principios. 2. Destinos aduaneros. 3. Tratamientos especiales. 4. Elementos de logística. IV. Conclusiones. V. Referencias.

\section{Introducción}

Durante 17 años, el comercio exterior colombiano estuvo regulado por el Decreto 2685 de 1999, Estatuto Aduanero, el cual sufrió numerosas modificaciones a través de varios decretos y sus respectivas resoluciones reglamentarias. No obstante lo anterior, no fueron los instrumentos de orden legal los únicos que en cierta medida modificaron la legislación aduanera, pues a través de circulares, memorandos, oficios y conceptos emitidos por la Dirección de Impuestos y Aduanas Nacionales - DIAN, entre otros actos administrativos, en la última década crearon un universo paralelo al sistema jurídico, en donde, en la mayoría de ocasiones, los usuarios aduaneros y los mismos funcionarios se remitían a estos para aplicar la norma de acuerdo al caso en particular.

Esta proliferación de normas generó una inestabilidad jurídica para los administrados, más aun si se tiene en cuenta que algunas interpretaciones realizadas por los funcionarios aduaneros determinaban el alcance o la prohibición de operaciones habituales del comercio; tal es el caso de la nacionalización de materias primas en zonas francas, donde a través del Concepto DIAN 048208 - 2014, se consideró que dicha actividad extralimitaba las funciones de los usuarios calificados del régimen franco al no estar contemplada dentro de las operaciones concebidas en la Ley 1004 de 2005, y en un mismo sentido, esto atentaba contra el principio de extraterritorialidad de que gozan las zonas francas al no ser consideradas parte del territorio aduanero nacional.

El Acto anteriormente referido fue revocado mediante el Concepto DIAN 108 (2181) de 2015, indicando que la ley en mención no señala la operación de forma taxativa, pero tampoco restringe la nacionalización de materias primas por parte de los usuarios industriales y comerciales, por lo que la autoridad aduanera no podría limitar el ejercicio de la actividad por medio de una interpretación extensiva, pues esta equivaldría a regular una actuación en particular. No obstante su revocatoria, durante la vigencia del anterior concepto se causaron serias dificultades para las empresas que hacen uso del instrumento, hasta el punto de replantear su modelo de negocio con el fin de continuar sus operaciones y no afectar los encadenamientos productivos realizados con otros actores.

Casos como el anteriormente ilustrado marcaban la necesidad de compilar las abundantes normas expedidas sobre la materia y actualizar las operaciones en un contexto internacional de cara a los compromisos con nuestros socios comerciales, derivados de los tratados de libre comercio suscritos. Vale la pena señalar que los instrumentos de promoción al comercio exterior fueron retirados del articulado en una de las últimas versiones del proyecto de regulación por motivos que se explicaran posteriormente.

En el año 2009, el gobierno nacional inició el arduo trabajo de modernizar la legislación aduanera en compañía del sector privado, proceso que se vio obstaculizado por distintos motivos políticos y jurídicos; recorde- 
mos que por orden del Tribunal Superior de Cartagena se ordenó suspender el trámite del proyecto de decreto, casi por un año, hasta tanto no se surtieran las consultas previas con las comunidades afrodescendientes de la región Caribe para las operaciones de cargue y descargue en fondeo.

El fallo en comento fue confirmado por la Sala de Decisión de Tutelas n. ${ }^{\circ} 2$ de la Sala de Casación Penal de la Corte Suprema de Justicia, en Sentencia del 3 de abril de 2014, finalmente revocada por medio de la Sentencia T- 46 de 2014 de la Corte Constitucional, que nuevamente dio vía libre al trámite de la nueva regulación, siempre y cuando se retirara del texto la actividad de fondeo, bajo el entendido de que dicha operación es del resorte de la Dirección General Marítima DIMAR. Este último punto lo consideramos lamentable si tomamos en cuenta que el fondeo es una operación común en el comercio internacional y que en algunas zonas del país, como la región del Urabá antioqueño, hacen uso para la exportación de productos, especialmente el banano.

Resuelto el inconveniente legal, se reactivaron las mesas de trabajo a inicios del año 2015, en cabeza del Director General de la DIAN, Santiago Rojas Arroyo y su equipo de trabajo, coordinado por el Consejo Gremial Nacional -CGN- ampliado, es decir, la participación de los 21 gremios pertenecientes al organismo, en donde se destacaron la Asociación Nacional de Comercio Exterior -Analdex-, la Asociación Nacional de Empresarios de Colombia -ANDI-, la Federación Nacional de Comerciantes -FENALCO-, la Federación de Aseguradores Colombianos -FASECOLDA-, la Asociación Colombiana de Pequeñas y Medianas Empresas -ACOPI-, la Asociación Colombiana de Industrias Plásticas -ACOPLÁSTICOS-, la
Asociación Colombiana de Exportadores de Flores -ASOCOLFLORES- y la Federación Colombiana de Transportadores de Carga por Carretera-COLFECAR; se sumaron a este grupo otras federaciones y asociaciones del comercio exterior que no hacen parte del Consejo Gremial Nacional.

Este nutrido grupo de trabajo, aunado a la buena disposición del sector público para lograr un texto definitivo, permitió nuevamente revisar temas que se consideraban cerrados en administraciones anteriores, ligados a las formalidades y operaciones de comercio exterior, las obligaciones de los declarantes y operadores de comercio exterior, los tratamientos especiales incorporados en la versión del proyecto de febrero del año 2015, y el régimen sancionatorio, este último considerado por mucho tiempo el menos flexible y sujeto a pocas modificaciones por parte de la DIAN. Este proceso de discusión se enmarcó en el principio de facilitación al comercio, sin perjuicio del control realizado por la autoridad aduanera.

Después de siete años, 200 mesas de concertación y 1.200 horas de trabajo, se expidió el siete de marzo de 2016 el Decreto 390, por el cual se establece la regulación aduanera, que responde a la búsqueda del fortalecimiento de los criterios de gestión de riesgo en el ejercicio del control aduanero; la sistematización de los procesos, compilación, modernización, armonización, y adecuación de las normas a mejores prácticas internacionales, tomando como base los principios y normas del Convenio Internacional para la Simplificación y Armonización de los Regímenes Aduaneros - Convenio de Kyoto Revisado-CKR-; las decisiones de la Comunidad Andina-CAN-y las recomendaciones de la Organización para la Cooperación y el Desarrollo Económicos -OCDE-. 


\section{Estado actual y problemática}

Diversas investigaciones elaboradas por entidades nacionales e internacionales han abordado el estudio del desempeño de los trámites y operaciones comerciales o border procedures and time, de los cuales solo trataremos los presentados por el Centro de Comercio Internacional -ITC- (por sus siglas en inglés), y el Banco Mundial-BM-, con el fin de identificar los "cuellos de botella" y obstáculos que afectan el comercio exterior colombiano.

\section{Colombia: perspectivas empresariales.}

\section{Serie del ITC sobre las medidas no}

\section{arancelarias}

El ITC y el Ministerio de Comercio, Industria y Turismo realizaron este estudio con el propósito de identificar las medidas no arancelarias y obstáculos que afectan a los empresarios colombianos y restan competitividad al país. El trabajo indica que un $48 \%$ de las empresas encuestadas (de una muestra de 731 empresas), que realizan operaciones de importación y exportación, presentan una afectación en sus operaciones hasta en un $40 \%$ y $26 \%$, respectivamente, lo que indica que hay dificultades en los procedimientos tanto de entrada como en la salida de mercancías. Estas cifras solo se reducen cuando las empresas realizan únicamente uno de los segmentos.

La siguiente gráfica muestra que el $98 \%$ de las trabas en materia de importaciones son originadas en Colombia, mientras que en las exportaciones, el porcentaje se reduce a un $25 \%$, cifra que impacta de forma significa las políticas de promoción y diversificación de las exportaciones y la necesidad de integrarnos en las cadenas globales de valor.

Analizando en detalle cuáles son obstáculos que registran los empresarios al momento de importar, se encuentran los siguientes:

En primer lugar encontramos los problemas en las diligencias de inspección realizadas por las entidades de control intervinientes, a saber: DIAN, Policía Antinarcóticos, Instituto Colombiano Agropecuario -ICA-, y el Instituto Nacional de Vigilancia de Medicamentos y Alimentos -INVIMA-, además de las realizadas por las navieras y puertos. Seguido, tenemos las evaluaciones de conformidad y requisitos técnicos, que corresponde a los estándares de calidad para salvaguardar la salud y seguridad nacional.

\section{Gráfica 1}

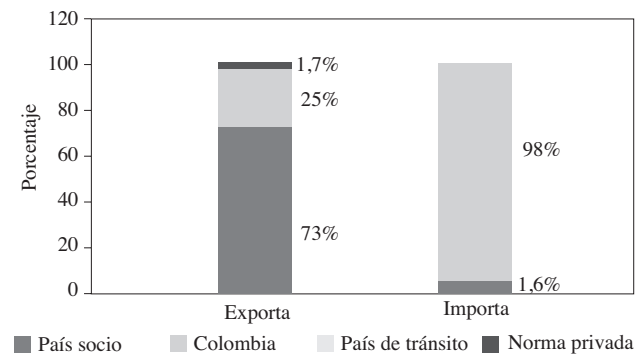

Fuente: Tomado de Colombia: Perspectivas empresariales. Serie del ITC sobre las medidas no arancelarias (2015).

\section{Gráfica 2}

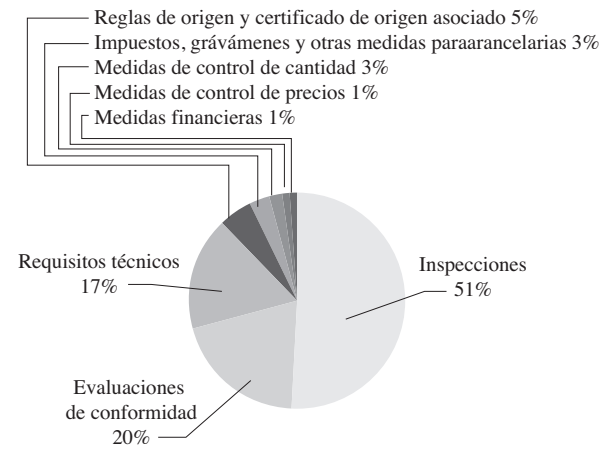

Fuente: Tomado de Colombia: Perspectivas empresariales. Serie del ITC sobre las medidas no arancelarias (2015).

Ahora, en cuanto a las exportaciones, vemos que comparten la misma dificultad, esto 
es, las inspecciones, particularmente realizadas por la DIAN y la Policía Antinarcóticos, situación que se agrava cuando no se dispone de medidas para realizar inspecciones simultáneas por parte de los entes de control mencionados, ni los equipos de inspección no intrusiva, lo que genera extra tiempos que finalmente se traducen en mayores costos para el empresario.

\section{Gráfica 3}

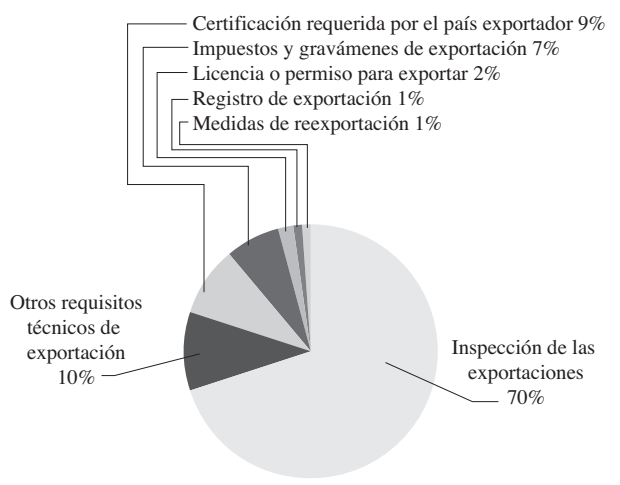

Fuente: Tomado de Colombia: Perspectivas empresariales. Serie del ITC sobre las medidas no arancelarias (2015).

De lo anterior, podemos colegir que la mayoría de los obstáculos identificados no corresponden al cumplimiento de normas aduaneras, sino que los cuellos de botella se encuentran en los procedimientos y trámites asociados al cumplimiento de la misma.

\section{Doing business}

Según el último reporte del Doing Business del BM (2016), el tiempo tomado para realizar una exportación en Colombia es de 112 horas, mismo término empleado para las importaciones; esto significa que una importación en promedio toma alrededor de 4,6 días. Si comparamos a Colombia con los países de América Latina y el Caribe, la media se encuentra en 107 horas, esto quiere decir que nos encontramos por encima de la media regional y mucho más alejados del promedio de los países pertenecientes a la OCDE con tan solo 9 horas. Este último aspecto es de importancia capital, teniendo en cuenta el interés de Colombia de pertenecer a este selecto grupo de países.

Aunado al anterior panorama, nuestro país ha adquirido compromisos con sus socios internacionales, particularmente con Estados Unidos, a través del tratado de libre comercio suscrito con el país norteamericano y que entró en vigencia en 2012; asimismo, el acuerdo suscrito con Chile, México y Perú, a través de la Alianza del Pacífico, en donde se contempló un término de nacionalización, hoy desaduanamiento, de 48 horas.

Revisando algunos casos de éxito en otros países, vemos cómo Japón (gráfica 5), de la mano de la Organización Mundial de Aduanas-OMA-, en dos décadas logró disminuir en 105,8 horas sus tiempos para el desaduanamiento de mercancías, gracias al desarrollo tecnológico de los servicios informáticos utilizados por la aduana; aspectos como la presentación de la declaración aduanera previo al arribo, la implementación de programas del operador económico autorizado -OEA-, y el continuo monitoreo y evaluación de sus procesos por medio de instrumentos para el estudio de tiempos de despacho -ETD-, los cuales deberán ser implementados en Colombia para finales de este año, resultarían del todo oportunos a efectos de obtener una medición más fiel de los tiempos, antes y después de la entrada en vigencia del Decreto 390 de 2016 y nuevamente en un par de años, el resultado se podrá comparar con los efectos y procedimientos introducidos en la nueva regulación aduanera. 


\section{Gráfica 4}

Cambios en el tiempo promedio rquerido desde la llegada al despacho (carga marítima)

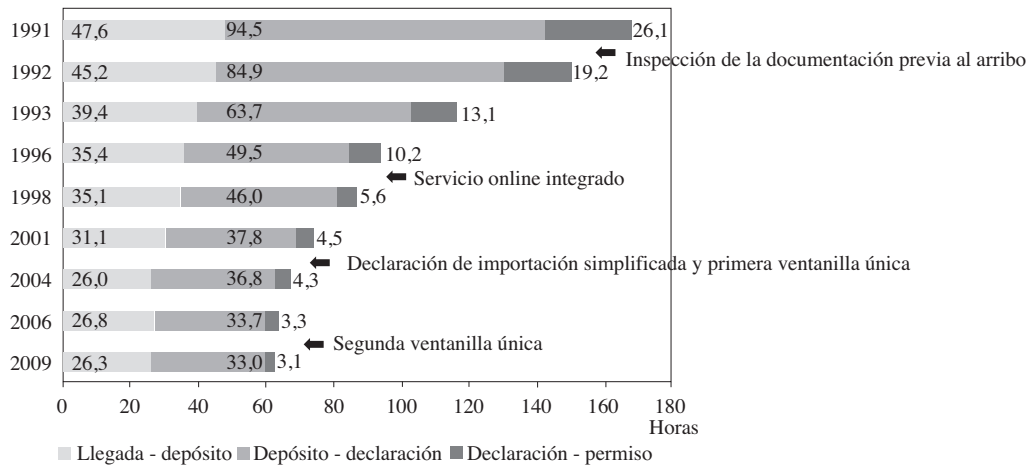

Fuente: Guía para la medición del tiempo requerido para el despacho de las mercancías. Versión 2 (2011).

\section{Gráfica 5}

Colombia - posición índice desempeño logístico (entre 160 países) 2014 - 2016

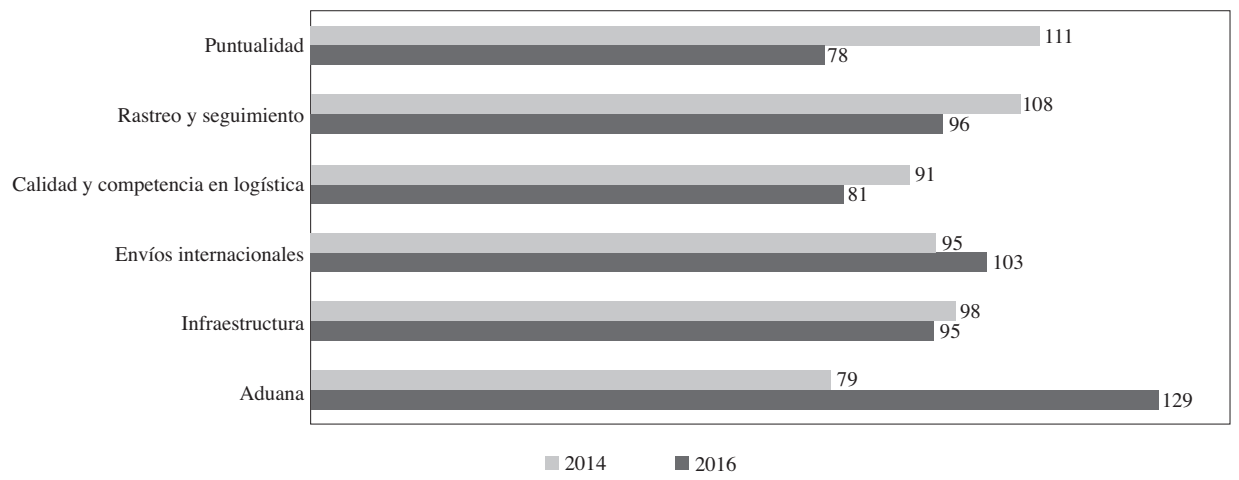

Fuente: Analdex a partir de datos LPI Connecting to Compete. BM (2016).

\section{3. Índice de desempeño logístico}

El último y más reciente estudio sobre la materia, también del BM, trata el Índice de Desempeño Logístico (2016) que tiene como fin medir el desempeño de la cadena logística de abastecimiento de un país; asimismo, dicho índice les permite a los países identificar oportunidades y desafíos para mejorar en cada uno de los factores tenidos en cuenta en este índice comparativo.

Dicho índice tiene en cuenta los siguientes factores: aduana, entendida como la eficien- cia del proceso de despacho (la velocidad, la sencillez y la previsibilidad de los trámites) por los organismos de control fronterizo; infraestructura, referida a la calidad de la infraestructura relacionada con el comercio y el transporte (por ejemplo, puertos, ferrocarriles, caminos, tecnología de la información); envíos internacionales, es decir, la facilidad de tramitar los embarques a precios competitivos; calidad y competencia en logística (la competencia y la calidad de los servicios de logística, por ejemplo, operadores de transporte, agentes de aduanas, 
entre otros); rastreo y seguimiento, que comprende la capacidad para rastrear y seguir los envíos, y puntualidad, entendida como el plazo de presentación de los envíos dentro del plazo de entrega programada o prevista (Gómez, 2016).

De acuerdo con la gráfica 5 , observamos que hemos avanzado en los factores de puntualidad, rastreo y seguimiento, calidad, y competencia en logística, e infraestructura; sin embargo, en cuanto al factor de aduana, que es de nuestro interés, Colombia presenta una caída de 50 posiciones respecto a la última evaluación realizada en el año 2014.

Identificados los anteriores problemas, podríamos agruparlos en i) dificultades para el cumplimiento de procedimientos asociados con los controles aduaneros, ii) demoras en las operaciones de comercio exterior e iii) ineficiencia en los procesos de despacho. A continuación trataremos los cambios de la nueva regulación aduanera que contribuirán, en cierta medida, a la solución de los obstáculos del comercio.

\section{Principales cambios de la nueva regulación aduanera}

\section{Principios}

Una de las principales modificaciones incorporadas y una evolución en cuanto al derecho aduanero es el desarrollo de los principios, pues la anterior legislación solo consagraba aquellos del artículo tercero del Código Contencioso Administrativo, hoy Código de Procedimiento Administrativo y de lo Contencioso Administrativo-CPACA-, y de manera expresa los principios de eficiencia y justicia. También hay autores que resaltan que no solo los principios menciona- dos rigen la materia aduanera pues también deben considerar los siguientes:

Los principios constitucionales del derecho tributario y del derecho administrativo irradian el derecho aduanero, y deben ser tenidos en cuenta tanto en el momento de producción de las normas de esta especie, como en el de su aplicación en cada caso concreto (Schlesinger et al., 2009, p. 88).

Según Sentencia C-818 de 2005, los principios están llamados a cumplir, en cualquier sistema normativo, los siguientes papeles principales: i) Sirven de base y fundamento de todo el ordenamiento jurídico; ii) actúan como directriz hermenéutica para la aplicación de reglas jurídicas y, finalmente, iii) en caso de insuficiencia normativa concreta y específica, se emplean como fuente integradora del derecho (Sentencia C-818 de 2005).

Teniendo en cuenta lo anterior, el Decreto 390 de 2016 abarca tanto los principios de la ley marco de comercio exterior -Ley 1609 de 2013-, como los previstos en el artículo tercero del CPACA y del Código General del Proceso, además los siguientes contenidos en el artículo segundo:

\section{Principio de eficiencia.}

2. Principio de favorabilidad.

3. Principio de justicia.

4. Principio de seguridad y facilitación en la cadena logística de las operaciones de comercio exterior.

5. Principio de prohibición de doble sanción por la misma infracción o aprehensión por el mismo hecho.

6. Principio de tipicidad.

7. Principio de prohibición de la analogía.

8. Principio de especialidad.

9. Principio de prevalencia de lo sustancial. 
Son los últimos cinco los que merecen especial atención, ya que se trata de principios propios del Derecho penal ajustados al sistema jurídico aduanero; su función es brindar seguridad al administrado y otorgar herramientas de defensa dentro de los procesos administrativos sancionatorios y de decomiso de mercancía.

Regresando al CKR, el principio de prevalencia de lo sustancial debe ser visto a la luz del convenio internacional, teniendo en cuenta el capítulo 3 del Anexo General, que expresa:

La autoridad aduanera no impondrá multas excesivas por errores cuando considere que los mismos fueron involuntarios sin intención fraudulenta o grave negligencia. Cuando considere necesario evitar la reincidencia de tales errores, podrá imponer una multa, pero la misma no será mayor que lo necesario a tales efectos (Convenio internacional para la simplificación y armonización de los regímenes aduanera (revisado). Anexo general, capítulo 3).

Además, según Peña et al. (2016), este principio denota gran importancia puesto que el régimen aduanero trata una materia altamente regulada, en donde el cumplimiento de los procedimientos es fundamental para la realización de las operaciones de comercio exterior.

Fue en el año 2015, con la expedición del Decreto 993, más conocido como "mercancía diferente", cuando se empezó a marcar un cambio en la filosofía de la DIAN, pues dicho Decreto resolvió un problema que afectaba a los importadores; la contingencia se refería a que el 70\% de las aprehensiones correspondían a errores formales en la descripción mínima de la declaración de importación, lo que indicaba que el control aduanero no estaba focalizado en los verdaderos delitos de contrabando y fraude aduanero, entre otros de similar naturaleza.

Es así como la nueva regulación recoge la norma antedicha y evita la imposición de sanciones por errores u omisiones en la descripción de la mercancía, siempre y cuando estos no se presenten en el serial, ni se trate de mercancía diferente que deba entenderse como de obligatorio cambio en la naturaleza de la mercancía declarada, frente a la verificada física o documentalmente. Una evolución de la figura es que elimina como causal de aprehensión los errores u omisiones en la declaración por temas de marca.

Igualmente, no puede dejarse de lado el nuevo concepto de análisis integral, que si bien se encontraba en el anterior estatuto aduanero, ahora se ha fortalecido, dándole una definición específica y estableciendo su aplicación para todos los regímenes aduaneros bajo las siguientes reglas o momentos: i) control previo; ii) simultáneo o posterior, y iii) en los procesos de fiscalización aduanera, previendo para cada uno la aplicación o utilización de diferentes documentos o soportes, resaltando para el último caso la libertad probatoria.

Por último, consideramos que el principio de tipicidad se ve trasgredido con la aplicación de la infracción tipo general o en blanco, que aplica por el incumplimiento de obligaciones derivadas de una formalidad aduanera, y que comprende todas las actuaciones o procedimientos que deben llevarse a cabo en cumplimiento de la legislación aduanera. En otras palabras, se trata de una sanción residual que podría obedecer a la discrecionalidad del funcionario en tanto las formalidades las encontramos a lo largo y ancho del articulado, siendo de difícil iden- 
tificación y violando los elementos propios del principio, al indicar que la infracción, hecho u omisión, deberá estar descrita de manera i) completa, ii) clara e iii) inequívoca.

\section{Destinos aduaneros}

Una nueva figura, tomada de la Decisión 671 de la CAN, es la destinación que se debe dar a las mercancías introducidas desde el exterior al territorio aduanero nacional, bajo potestad aduanera, y que está regulada por la nueva legislación en el artículo 138.

De lo anterior tenemos que el destino comprende el tratamiento aplicable a las mercancías al momento de su ingreso al territorio aduanero nacional, según el proyecto de reglamentación de la regulación aduanera; la destinación se realiza cuando la mercancía se encuentre en lugar de arribo o un depósito temporal y no requiere del diligenciamiento de una declaración aduanera. Su trámite se realiza a través de los servicios informáticos electrónicos.

Más importante aún es el efecto del destino, pues determinará el proceso, trámites y formalidades que se deben desarrollar de acuerdo con los procedimientos de cada uno, y a su vez, la autoridad aduanera podrá realizar el monitoreo de las mercancías y verificará el cumplimiento de las obligaciones del declarante y operadores de comercio exterior.

En este sentido, los destinos aduaneros en nuestra legislación son:

1. La inclusión de las mercancías en uno de los regímenes aduaneros de tránsito, depósito aduanero o de importación.

2. La introducción a un depósito habilitado.

3. La destrucción.

4. El abandono.

\section{El reembarque.}

Teniendo en cuenta que entrar al estudio de cada de los destinos nos alejaría del objeto de este escrito y representaría por lo menos dedicar un par de cientos de páginas, realizaremos únicamente tres comentarios sobre el tema.

El primer comentario está relacionado con las zonas francas y los instrumentos de promoción de comercio exterior en general, entre los que encontramos las sociedades de comercialización internacional, los sistemas especiales de importación exportación-Plan Vallejo-, y las zonas especiales económicas de exportación, los cuales fueron retirados del texto de la nueva regulación aduanera con ocasión del traslado de funciones que realizó la DIAN al Ministerio de Comercio, Industria y Turismo, por medio del Decreto 1289 de 2015.

Por lo anterior, la aduana no podría regular las operaciones de estas figuras hasta tanto no se expidan los decretos y resoluciones de política correspondiente a cada uno de ellos, destacando necesariamente que al momento de elaboración de este escrito aún se encuentran en fase de proyecto.

Hacemos la aclaración en este punto, porque las zonas francas son un destino aduanero, pero por los motivos antes mencionados, no se encuentra ninguna mención en la nueva regulación. Creemos que esto generará muchas dificultadas al momento de sincronizar las operaciones de comercio exterior con los instrumentos. Claro ejemplo de lo anterior ocurrió con el proyecto de zonas francas, en una de cuyas versiones, ad portas de ser firmado por los ministerios involucrados, se detectó que la remisión del proyecto del régimen franco a la regulación aduanera para las operaciones de tránsito aduanero no permitía la finalización en dichos lugares. 
Una segunda apreciación se hace en relación con el destino de depósito habilitado, el cual, a través de la Resolución reglamentaria 41 de 2016, fue delimitado únicamente al depósito franco. Consideramos que la resolución extralimitó el alcance de la norma, pues el Decreto en ningún momento señaló que el artículo estaba sujeto a reglamentación.

Por último, tenemos que el único destino que hoy se encuentra en vigencia es el reembarque. Esto gracias a dos artículos, bastante ingeniosos por cierto, que permiten, cuando no se hayan desarrollado o implementado los ajustes a los servicios informáticos electrónicos, aplicar i) procedimientos alternativos y/o ii) continuar aplicando los ya existentes.

No obstante, la aplicación de estos métodos alternos debe ser excepcional y no corresponde a la regla general, dado que varios artículos en el proyecto de reglamentación adoptan el mismo método, contrariando la exposición de motivos de la regulación en busca de sistematización de procesos y desarrollo de los servicios informáticos.

En este orden de ideas, la resolución reglamentaria indica que el destino de reembarque tendrá el mismo procedimiento como modalidad de exportación, sin que haya lugar a que se trate de un régimen, aun así finalice con una declaración exportación, de acuerdo con el Decreto 2685 de 1999 y la Resolución 4240 de 2000, de la siguiente forma:

\section{Gráfica 6}

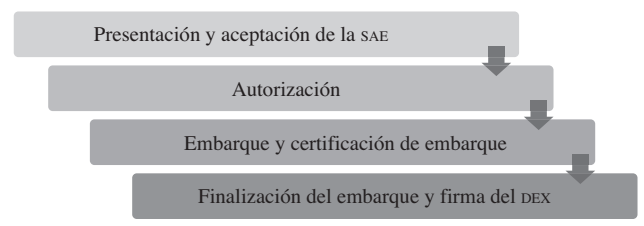

Fuente: Elaboración propia.

\section{Tratamientos especiales}

La nueva regulación adiciona dos nuevas figuras denominadas i) exportador autorizado y ii) usuarios de confianza. Recordemos que la OEA, aun cuando hace parte de este grupo, tiene su propia legislación por medio del Decreto 3568 de 2011, modificado por el Decreto 1894 de 2015.

Conocidas las figuras, revisaremos los principales beneficios que consagra la nueva regulación, los cuales serán determinantes en cuanto a facilitación y simplificación de las operaciones de comercio exterior:

a. Exportador autorizado: su origen se remonta a los tratados de libre comercio que reconocen la figura, ahora la regulación aduanera la incorpora en la legislación nacional y a través de ella permite a los exportadores autorizados expedir declaraciones de origen o declaraciones en factura, de acuerdo con lo establecido en cada acuerdo.

b. Importadores, exportadores y operadores de comercio exterior, de confianza: a diferencia de las otras dos autorizaciones, el reconocimiento de la calidad de confianza se realiza a través de calificación, es decir, es potestativa de la autoridad aduanera de acuerdo con los criterios de gestión del riesgo, que son:

i. Las personas que intervienen en la cadena logística de distribución y las características de la operación de comercio exterior.

ii.El estado de las obligaciones de pagos exigibles en materia tributaria, aduanera o cambiaria, sanciones, y demás acreencias a favor de la Dirección de Impuestos y Aduanas Nacionales.

iii. Los derivados del incumplimiento de las obligaciones tributarias, aduaneras y cambiarias. 
iv. Las relacionadas con la evasión del pago de los derechos e impuestos a la importación por distorsión de los elementos del valor en aduana de las mercancías importadas, de los tratamientos preferenciales derivados de la aplicación de las normas de origen y de los aspectos relativos a la nomenclatura arancelaria.

v. La solvencia económica para desarrollar las operaciones de comercio exterior y el origen de los fondos.

vi. La solvencia económica necesaria que asegure el cumplimiento de sus obligaciones tributarias, aduaneras y cambiarias.

No obstante lo anterior, la DIAN tendrá en cuenta otros criterios no contemplados en los arriba enunciados, y que no fueron publicados en la regulación, lo cual puede generar inconvenientes al momento de la calificación de los usuarios y atenta contra la transparencia de los procesos. Es importante conocer los criterios a fin de desarrollar oportunidades de mejora y así acceder a la calificación.

El sistema de gestión de riesgos se constituye como la columna vertebral de la nueva regulación, derivado del principio de seguridad y facilitación en la cadena logística de las operaciones de comercio exterior, en la medida que permitirá a la autoridad aduanera concentrarse en el control sobre los obligados aduaneros y sobre la operación, no sobre la mercancía.

Además, dependiendo del perfil del riesgo, el cual podrá ser bajo, medio o alto, permitirá definir si un obligado se encuentra sujeto a control permanente-alto-, o por el contrario accede a un tratamiento especial -bajo-.

La regulación aduanera, en su artículo 35, contempla 11 beneficios para el usuario de confianza, dentro de los que destacamos: i. Efectuar el pago consolidado de los derechos e impuestos a la importación, las sanciones, intereses y valor del rescate, a que hubiere lugar, dentro de los cinco días hábiles siguientes de cada mes, derivados de las declaraciones aduaneras presentadas en este período.

ii. Realizar el pago diferido de los derechos e impuestos a la importación dentro del mes siguiente a la importación, contados a partir de la autorización de retiro de las mercancías.

iii. Constituir una sola garantía global que ampare varios registros aduaneros; en este caso se deberá constituir una garantía sobre el mayor valor asegurado, incrementado en un $20 \%$ del valor de cada uno de las demás.

iv. Realizar el aforo en las instalaciones del exportador; este beneficio disminuirá considerablemente los tiempos de despacho de mercancías, reduciendo los costos de operación y, a su vez, incrementando la competitividad del país. Sin embargo, para la realización de la diligencia, es necesaria la coordinación de las entidades de control intervinientes.

v. Realizar el desaduanamiento abreviado. Podría considerarse uno de los mayores beneficios concebidos y el que plantea una reducción sustancial en los tiempos de importación para cumplir con el desaduanamiento de 48 horas. Consiste en la entrega de la mercancía en el lugar de arribo con la presentación de una declaración simplificada de manera anticipada, que contenga el mínimo de información requerida la cual posteriormente será complementada a través de otra declaración, con el pago diferido o consolidado de los derechos e impuestos a la importación.

Para observar el alcance del tratamiento es necesario conocer el nuevo proceso de 
importación, que comprende las siguientes etapas:

\section{Gráfica 7}

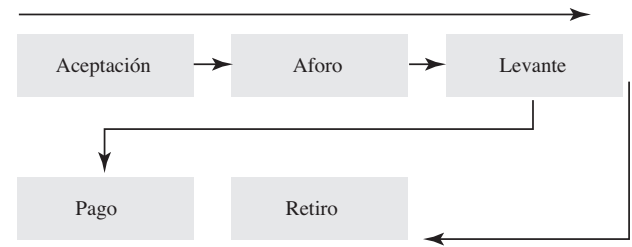

Fuente: Elaboración propia.

Ahora bien, el proceso se reduciría únicamente a las etapas de aceptación, teniendo en cuenta que en su calidad de confianza tiene un porcentaje bajo de aforos por lo que procedería el levante automático. Omitimos el pago ya que este se realizará consolidado o diferido, por lo que obtendría una autorización de retiro prácticamente inmediata, ya que la última actuación solo se encarga de revisar el levante y el pago.

c. Operador económico autorizado: además de las contempladas en el artículo 35, que corresponden a nueve beneficios, también abarca los 11 de los usuarios de confianza. Resaltamos los siguientes por su importancia:

i. No constituir garantías.

ii. Realizar el desaduanamiento de las mercancías en las instalaciones del declarante.

iii. Presentar la solicitud de autorización de embarque en el lugar de embarque.

iv. Someter la mercancía a régimen de depósito aduanero, una vez ha finalizado el régimen de tránsito o una operación de transporte multimodal o una operación de transporte combinado.

v. Reducir el valor de rescate para los siguientes casos:

\section{Gráfica 8}

\begin{tabular}{lcc}
\hline Caso & Rescate & Reducción \\
\hline $\begin{array}{l}\text { Cuando la mercancía se encuentre en } \\
\text { situación de abandono. }\end{array}$ & & \\
\hline $\begin{array}{l}\text { Cuando exista mercancía respecto } \\
\text { de la cual se hubiere configurado su }\end{array}$ & $5 \%$ CIF \\
abandono legal, por no haberse obte- & $5 \%$ CIF \\
nido la autorización de retiro dentro & \\
del término. & \\
\hline $\begin{array}{l}\text { Cuando transcurridos } 30 \text { días calen- } \\
\text { dario, contados a partir de la autori- }\end{array}$ & \\
zación de retiro, se detectan errores & $5 \%$ CIF \\
u omisiones en la descripción de la \\
mercancía de la declaración, siempre \\
y cuando no haya intervenido la au- \\
toridad aduanera.
\end{tabular}

Fuente: Elaboración propia.

\section{Elementos de logística}

Son varios los instrumentos contemplados en la nueva regulación con el objeto de reducir los tiempos de las operaciones de comercio exterior, facilitar los procedimientos aduaneros y agilizar los trámites de control. Entre ellos encontramos:

a. Prestación del servicio veinticuatro horas al día, los siete días de la semana. Vale la pena mencionar que durante la discusión de varios de los proyectos de regulación se trató de una obligación para algunos operadores de comercio exterior, como puertos, aeropuertos, entre otros; sin embargo, se modificó obedeciendo a las necesidades del mercado, es decir, únicamente cuando la operación la requiera.

b. Dispositivos electrónicos de seguridad: permite realizar un monitoreo permanente a la mercancía que se encuentren en tránsito aduanero, brindando seguridad en la cadena logística y ejerciendo el control por parte de la DIAN. Es de anotar que incluso con los dispositivos, la aduana tiene la potestad de restringir los tránsitos con base en la gestión del riesgo. 
c. Inspección simultánea: indica que las autoridades de control que intervengan en una diligencia de aforo o reconocimiento deberán actuar de manera coordinada.

d. Depósitos aduaneros: permite declarar la mercancía en el régimen de depósito aduanero para el almacenamiento de mercancías por un año prorrogable por otro año.

e. Centros de distribución logística internacional: anteriormente conocidos como los depósitos de apoyo logístico internacional que se ajustan al nuevo lenguaje con el fin de acceder al beneficio del estatuto tributario; esto es, que las transacciones de mercancías extranjeras propiedad de no residentes realizadas en estos centros, están libres de impuesto de renta. El término de permanencia es igual al de los depósitos aduaneros.

\section{Conclusiones}

Son varias e importantes las modificaciones incorporadas en el Decreto 390 de 2016 para la facilitación y simplificación de las operaciones de comercio exterior; sin embargo, no hemos podido percibir sus efectos en la medida que la entrada en vigencia es escalonada, es decir, los artículos se encuentran distinguidos en tres grupos para efectos de su entrada en vigencia: i) aplicación inmediata a partir del 22 de marzo del presente año, ii) pendientes de reglamentación dentro de los 180 días siguientes a su publicación y iii) sujetos a los ajustes informáticos electrónicos, lo que podría tomar hasta dos años.

Esto ha generado una incertidumbre para los obligados aduaneros, en la medida en que no tienen seguridad respecto de la entrada en vigencia de las normas, sin contar con los oficios, memorandos y conceptos que ya se han expedido sobre el particular, tratando de aclarar la aplicación de las normas.

Los tratamientos especiales, sin duda alguna, serán el vehículo para agilizar los procesos, pero teniendo en cuenta la experiencia del OEA, en donde solo se han calificado 17 empresas exportadoras en los últimos tres años, representa una dificultad para el sector privado obtener alguna de las calidades, siendo este un llamado a los privados a iniciar su proceso de mejoramiento para cumplir con los estándares exigidos en la norma. Es importante mencionar que los usuarios aduaneros permanentes y altamente exportadores se descalificarán el 22 de marzo de 2020, por lo que es necesario migrar a alguna de las figuras y no perder de vista la competitividad como objetivo de esta nueva regulación.

El sistema de gestión del riesgo se alimenta de los servicios informáticos electrónicos; no obstante, no han tenido el desarrollo adecuado que soporten las nuevas operaciones, formalidades, destinos y regímenes, por lo que estamos -hasta el momento- con un híbrido en materia de vigencias normativas para el comercio de exterior, por cuanto aplica el anterior Estatuto Aduanero (Decreto 2685 de 1999) y la nueva regulación contenida en el Decreto 390 de 2016.

Por último, consideramos que es necesario hacer uso de las herramientas tecnológicas para ejercer el control de las mercancías, sin que esto en ningún momento implique la prohibición de las operaciones; debemos avanzar a un sistema inteligente de selección de acuerdo con el perfil de riesgo, evitando de esta forma redundar en procesos para aquellos declarantes u operadores exteriores que brinden confianza a la aduana. 


\section{Referencias}

\section{Bibliográficas}

Pardo Schlesinger, Cristina (2009). "Fundamentos constitucionales del derecho aduanero", en Parado Carrero, Germán. El derecho aduanero en el siglo XXI. Colección textos de jurisprudencia. Bogotá: Editorial Universidad del Rosario, p. 88. ISBN: 978-958-738-065-1.

Peña Preciado, Angélica y Potdevin Stein, Nicolás (2016). Panel: Comentarios al Estatuto Aduanero. Estudios de Derecho Tributario, Derecho Aduanero y Comercio Exterior, en Moreno Daza, Diego Andrés. 40 Jornadas Colombianas de Derecho Tributario, Derecho Aduanero y Comercio Exterior. Cartagena - Colombia 10, 11 y 12 de feb. 2016. p. 414. ISBN: 2422-1511

\section{Enlaces electrónicos}

Gómez, Giovanni (2016). Índice desempeño logística 2016. Disponible en http://www.analdex.org/2016/07/11/ indice-desempeno-logistico-2016/ 